\title{
PUSAT FASHION PONTIANAK
}

\author{
Asep Mauluddin', Hamdil Khaliesh², Irwin ${ }^{3}$ \\ ${ }^{1}$ Mahasiswa, Program Studi Arsitektur, Fakultas Teknik, Universitas Tanjungpura. \\ Asepmauluddin@gmail.com \\ ${ }^{2}$ Program Studi Arsitektur, Fakultas Teknik, Universitas Tanjungpura \\ ${ }^{3}$ Program Studi Arsitektur, Fakultas Teknik, Universitas Tanjungpura
}

Naskah diajukan pada: 7 Februari 2021

Naskah revisi akhir diterima pada: 11 Februari 2021

\begin{abstract}
Abstrak
Kalimantan barat memiliki banyak ragam budaya, suku, dan agama sehingga memiliki produk fashion khas pada setiap daerah seperti kain, songket, dan juga tenun yang sangat bervariatif. Banyaknya retail fashion juga berpengaruh terhadap minat dan daya tarik masyarakat terhadap perkembangan fashion di Pontianak. Fashion berkembang dengan pesat pada saat ini karna perkembangan teknologi dimana para anak muda mementingkan fashion untuk menunjang penampilannya. Oleh karena itu, dibutuhkan suatu Pusat Fashion di Pontianak yang dapat digunakan untuk memperkenalkan, memproduksi, memasarkan dan yang terpenting adalah mempromosikan fashion khas daerah kalimantan barat. Perancangan gedung ini menggunakan metode yang membandingkan hasil observasi dengan studi literatur, studi banding dan standar yang berlaku untuk gedung fashion serta fasilitasnya, lalu menganalisis aspek-aspek internal dan eksternal yang diharapkan. Perancangan gedung Pusat Fashion Pontianak ini akan di integrasikan dengan kawasan sekitar, dan juga konsep bentuk bangunan yang diaplikasikan dari pakaian khas daerah agar dapat menjadi ikon baru kota Pontianak.
\end{abstract}

Kata-kata Kunci: Fashion, Pakaian tradisional, Galeri

\begin{abstract}
West Kalimantan has a wide variety of cultures, ethnicities, and religions so that it has distinctive fashion products in each region such as cloth, songket, and also very varied weaving. The number of retail fashion also affects the interest and attractiveness of the community towards the development of fashion in Pontianak. Fashion is growing rapidly at this time due to technological developments where young people attach importance to fashion to support their appearance. Therefore, we need a fashion center in Pontianak that can be used to introduce, produce, market and most importantly promote West Kalimantan regional fashion. This building design uses a method that compares the results of observations with literature studies, comparative studies and standards applicable to fashion buildings and facilities, then analyzes the expected internal and external aspects. The design of the Pontianak Fashion Center building will be integrated with the surrounding area, and also the concept of the shape of the building which is applied from traditional clothing so that it can become a new icon of the city of Pontianak.
\end{abstract}

Keywords: Fashion, Traditional clothes, Gallery

\section{Pendahuluan}

Fashion adalah gaya berpakaian yang digunakan setiap hari, baik dalam kehidupan sehari-hari maupun dalam acara tertentu yang tujuannya untuk menunjang penampilannya. Selain itu definisi Fashion diartikan sebagai gaya berpakaian yang populer dalam budaya atau mode. Beberapa orang beranggapan bahwa fashion adalah gaya berpakaian yang sangat menentukan penampilan seseorang. Kata Fashion berasal dari bahasa Inggris dan dapat diartikan sebagai mode, model, gaya ataupun kebiasaan. 
Pontianak pada saat ini adalah pusat kota di Kalimantan barat dimana menjadi kota ramai dan padat penduduk, termasuk para pendatang seperti pelajar, mahasiswa maupun pekerja dari luar kota. Gaya hidup masyarakatnya pun berubah mengikuti gaya hidup masyarakat kota besar. Hal ini terlihat jelas pada gaya berbusana dan penampilan masyarakat di Pontianak.

\section{Kajian Pustaka}

Pengertian pusat menurut Kamus Besar Bahasa Indonesia (2019) adalah titik tolak atau pumpunan (berbagai hal, urusan, dsb). Titik awalnya adalah definisi center (berbagai kasus, dan sebagainya). Sebuah tempat dengan aktivitas tinggi yang dapat menarik perhatian dari sekitarnya (Poerdarminto, 2003).

Menurut Kamus Besar Bahasa Indonesia (2019) pengertian fashion adalah ragam terbaru (metode, bentuk) pada waktu tertentu (tentang pakaian, model rambut, corak ragam hias, dll). Menurut Polhemus dan Procter, orang di dunia Barat menyebut fashion sebagai istilah yang mengekspresikan gaya, pakaian, dan dandanan. Oleh karena itu, tidak mengherankan jika dalam perkembangannya makna fashion hanya dipandang sebagai trend dan gaya fashion. Yang lebih berfokus pada penampilan dan kecantikan orang (Strathern, Polhemus dan Procter, 1979).

Menurut Yunita (2019) fungsi pusat fashion adalah untuk mengenalkan perkembangan produk fashion terkini kepada masyarakat luas khususnya produk lokal yang bertujuan untuk meningkatkan kesadaran masyarakat akan fashion terkini, serta menyediakan produk pakaian yang sesuai dengan minat konsumen, baik produk lokal maupun produk luar. Informasi dan notifikasi memberikan fasilitas acara informal untuk segala hal yang berkaitan dengan perkembangan fashion, sehingga membuat masyarakat dikenal sebagai konsumen. Serta mewadahi event-event yang berkaitan dengan dunia fashion, yakni melalui booth-booth yang menampung banyak perusahaan dagang lokal, nasional dan internasional. Dimaksudkan untuk semua pihak terkait dengan industri fashion dapat lebih mudah terhubung, antara lain: industri tekstil, serta investor yang tertarik mencari mitra bisnis. Manager Perhimpunan Perancang Mode Indonesia (PAPMI) Provinsi DIY (2009) dalam Yunita (2019) mengatakan ini merupakan langkah awal dalam pengembangan fashion, yang selalu mengacu pada promosi karya perancang busana dan memadukan ide dan penemuan zaman.

\section{Metode}

Pada perancangan gedung ini menggunakan metode yang membandingkan hasil observasi dengan studi literatur, studi banding dan standar yang berlaku untuk gedung fashion serta fasilitasnya, lalu menganalisis aspek-aspek internal dan eksternal.

Analisis dan konsep berarti menentukan kebutuhan dan suasana ruang, kemudian menerapkannya pada desain arsitektur. Pengelompokan ini terbagi menjadi dua bagian yaitu analisa internal dan analisa eksternal.

Analisis internal adalah analisis penulis terhadap fungsi dan sistem yang akan diterapkan pada desain. Analisis internal terbagi menjadi beberapa poin, yaitu: pengelompokan kegiatan, analisis pelaksana, kebutuhan ruang, oersyaratan ruang, hubungan ruang dan organisasi ruang. Pada saat yang sama, analisis eksternal akan mengarah pada kondisi lingkungan yang ada di lokasi desain. Analisis dibagi menjadi beberapa poin pembahasan yaitu: desain lokasi, analisis posisi, analisis vegetasi, analisis arah, analisis sirkulasi, analisis zonasi, sistem utilitas, dan sistem struktur.

Pengumpulan data dilakukan melalui observasi langsung di tempat, setelah semua data terkumpul maka dilakukan studi banding bangunan terkait dengan desain. Menganalisis hasil dengan mengkomparisasikan data yang telah didapat yang berkaitan dengan Pusat Fashion Pontianak. Data yang dianalisis mulai dari ruang yang dibutuhkan dan fungsi pada bangunan tersebut dilanjutkan dengan menganalisis struktur dan utilitas bangunan, menganalisis tapak lingkungan beserta arsitektur lingkungan untuk mendapatkan orientasi dan perletakan bangunan, sistem penghawaan, pencahayaan dan lain-lain. 
Dilanjutkan dengan Tahap konsep yaitu konsep perancangan berdasarkan analisis yang telah dilakukan. Kemudian tahap prarancangan merupakan tahap menuangkan hasil kedalam gambar kerja. Tahap pengembangan rancangan yaiu tahap lanjutan dari tahap prarancangan produk berupa gambar detail, power point, laporan, dan maket.

Site perancangan beralamat di Jalan Veteran, Kelurahan Benua Melayu Darat, Kecamatan Pontianak Kota. Pencapaian menuju bangunan mudah diakses karena berada di pusat kota dan dapat dilalui kendaraan bermotor. Bagian utara site berbatasan dengan Gg. Syukur 5, Bagian timur berbatasan dengan Jalan Veteran, sebelah barat berbatasan dengan Gg. Syukur 6, sedangkan selatan berbatasan dengan warung kopi (LCC). Site memiliki lahan seluas $\pm 0,84 \mathrm{Ha}( \pm 8.400 \mathrm{~m} 2)$.

\section{Hasil dan Pembahasan}

\section{Lokasi Perancangan}

Lokasi perancangan berada di Jalan Veteran, Kelurahan Benua Melayu Darat, Kecamatan Pontianak Kota. Luas lahan tersebut adalah 0,84 hektar dengan kondisi masih berupa lahan kosong yang pada saat ini masih rawa-rawa. Lokasi ini dapat dicapai melalui jalur darat. Area disekitar site merupakan area komersil yaitu kawasan perdagangan dan jasa.

Kota Pontianak merupakan Ibu kota provinsi Kalimantan Barat, dimana luas keseluruhan wilayahnya mencapai $\pm 107.82 \mathrm{Km}^{2}$. Kota Pontianak dilintasi oleh garis Khatulistiwa, yaitu pada $0^{\circ}$ 02' 24" Lintang Utara sampai dengan $0^{\circ}$ 05' 37" Lintang Selatan dan $109^{\circ} 16^{\prime} 25^{\prime}$ 'Bujur Timur sampaidengan $109^{\circ} 23^{\prime}$ 01" Bujur Timur. Ketinggian Kota Pontianak berkisar antara 0,10 meter sampai 1,50 meter diatas permukaan laut dan kemiringan tanah sekitar 0-2\%. Terdapat 2 sungai utama yaitu Sungai Kapuas dan Sungai Landak yang membelah Kota serta dikelilingi oleh sekitar 33 sungai kecil. Dilihat dari iklim Kota Pontianak merupakan iklim tropis yang terbagi menjadi dua (dua bagian) yaitu musim hujan dan musim kemarau. Dalam keadaan normal, musim kemarau terjadi pada bulan Mei hingga Juli, sedangkan musim hujan terjadi pada bulan September hingga Desember. Suhu udara rata-rata di Kota Pontianak mencapai $26,1^{\circ} \mathrm{C}-27,4^{\circ} \mathrm{C}$, dan kelembaban udara antara $86 \%$ sampai 92\%. Curah hujan tahunan berkisar antara $3000 \mathrm{~mm}-4000 \mathrm{~mm}$, sedangkan ketinggian daratan hanya antara $0,10-1,5 \mathrm{~m}$ di atas permukaan laut.

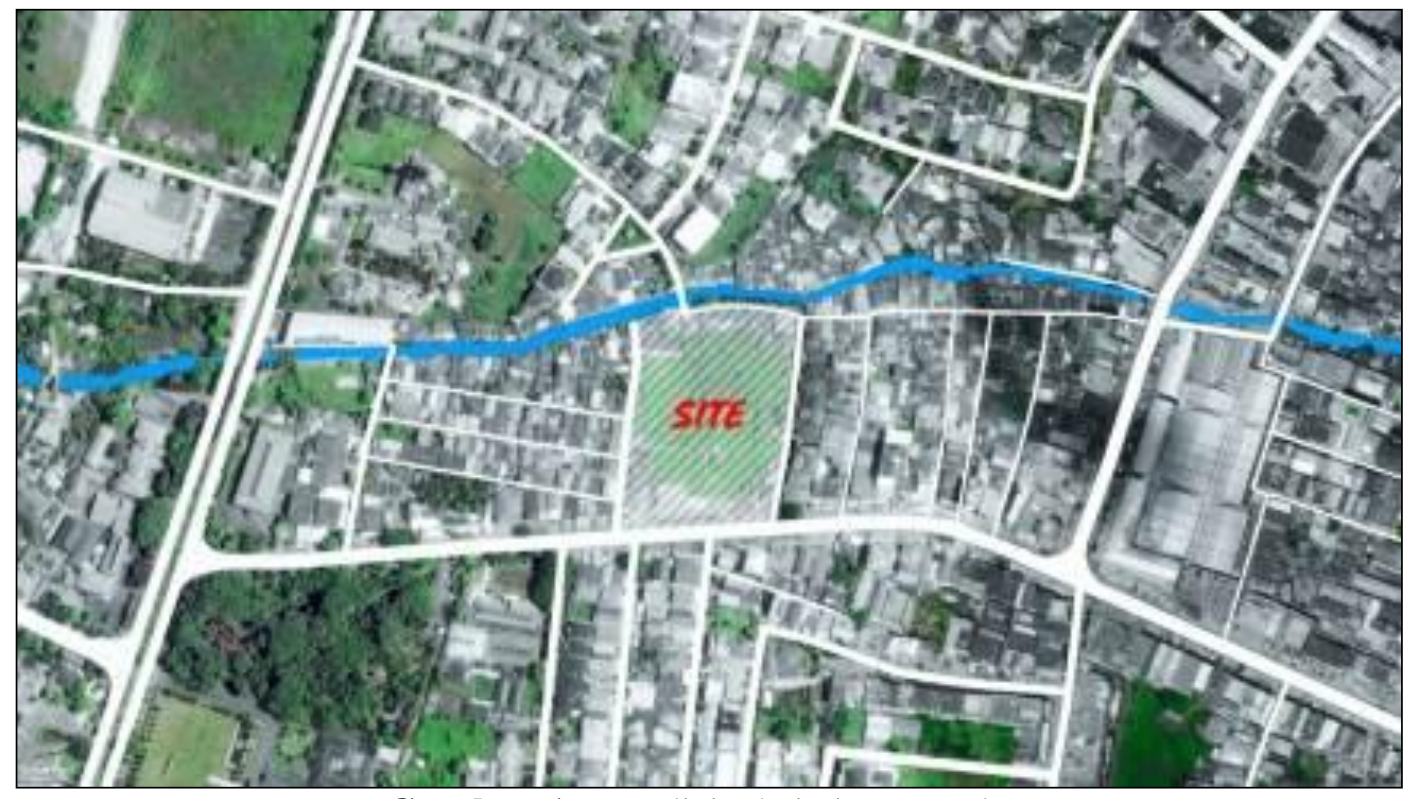

Gambar 1. Kondisi Eksisting Tapak

Sumber: Penulis, 2019 


\section{Landasan Konseptual}

Landasan konseptual, membahas analisis perancangan Pusat Fashion Pontianak serta konsep internal dan eksternal. Analisis dan konsep berarti menentukan kebutuhan dan suasana ruang, kemudian menerapkannya pada desain arsitektur. Pengelompokan ini terbagi menjadi dua bagian, yaitu analisis internal dan analisis eksternal. Analisis internal adalah analisis penulis terhadap fungsi dan sistem yang akan diterapkan pada desain. Analisis internal dibagi menjadi beberapa poin, yaitu: pengelompokan kegiatan, analisis pelaksana, kebutuhan ruang, permintaan ruang, hubungan ruang dan organisasi ruang. Pada saat yang sama, analisis eksternal akan mengarah pada kondisi atau kondisi lingkungan yang ada di lokasi desain. Analisis dibagi menjadi beberapa poin pembahasan yaitu: desain lokasi, analisis posisi, analisis arah, analisis sirkulasi, analisis vegetasi, analisis zonasi, sistem utilitas umum, dan sistem struktur.

Aktivitas di Pusat Fashion Pontianak dikelompokkan menurut aktivitas penggunanya. Pengelompokan kegiatan terbagi menjadi yaitu kegiatan pameran, kegiatan penjualan khususnya penyelenggaraan fashion show dan manajemen. Lebih detailnya dilihat pada Tabel 1.

Tabel 1. Analisis Internal

\begin{tabular}{|c|c|c|c|}
\hline Kegiatan & Wadah Fungsi & Detail & Pelaku \\
\hline Desain dan Produksi & Workshop & $\begin{array}{c}\text { Mendesain } \\
\text { Membuat pola } \\
\text { Cutting } \\
\text { Menjahit }\end{array}$ & $\begin{array}{l}\text { Desainer } \\
\text { Pegawai } \\
\text { Pembantu }\end{array}$ \\
\hline $\begin{array}{c}\text { Promosi dan } \\
\text { Pameran Fashion }\end{array}$ & $\begin{array}{c}\text { Ruang Pameran } \\
\text { Stage } \\
\text { Catwalk }\end{array}$ & $\begin{array}{c}\text { Mempromosikan } \\
\text { Barang saat Pameran }\end{array}$ & $\begin{array}{l}\text { Sales } \\
\text { Model }\end{array}$ \\
\hline Penjualan & $\begin{array}{l}\text { Ruang Butik } \\
\text { Gudang }\end{array}$ & $\begin{array}{c}\text { Belanja } \\
\text { Jalan-jalan } \\
\text { Melihat-lihat }\end{array}$ & $\begin{array}{l}\text { Owner butik } \\
\text { Penjaga toko }\end{array}$ \\
\hline \multirow[t]{6}{*}{$\begin{array}{l}\text { Pelayanan } \\
\text { Pendukung }\end{array}$} & Foodcourt & $\begin{array}{c}\text { Konsumen datang } \\
\text { Melayani Konsumen } \\
\text { Memesan, Kepentingan } \\
\text { Transaksi }\end{array}$ & $\begin{array}{c}\text { Manager, staf, } \\
\text { pegawai, masyarakat / } \\
\text { konsumen }\end{array}$ \\
\hline & Lobi & $\begin{array}{c}\text { Jalan-jalan } \\
\text { Berkomunikasi } \\
\text { Melihat-lihat }\end{array}$ & $\begin{array}{l}\text { Masyarakat / } \\
\text { Konsumen }\end{array}$ \\
\hline & Taman & $\begin{array}{c}\text { Jalan-jalan } \\
\text { Istirahat } \\
\text { Bertemu teman }\end{array}$ & $\begin{array}{l}\text { Masyarakat / } \\
\text { Konsumen }\end{array}$ \\
\hline & \multirow[t]{3}{*}{ Pengelola } & Kantor pelayanan & $\begin{array}{c}\text { Masyarakat / } \\
\text { Konsumen }\end{array}$ \\
\hline & & $\begin{array}{c}\text { Pertemuan Staf } \\
\text { Administrasi } \\
\text { Fasilitas }\end{array}$ & Pegawai \\
\hline & & $\begin{array}{l}\text { Penyimpanan } \\
\text { peralatan kebersihan } \\
\text { Penyimpanan peralatan } \\
\text { perawatan bangunan }\end{array}$ & Karyawan \\
\hline
\end{tabular}

Sumber: Penulis, 2019 
Kemudian, faktor eksternal seperti tapak, iklim, dan kebijakan wilayah diterapkan pada desain ruang eksterior bangunan. Kemudian, proses analisis denah luar ruang akan membentuk skema atau peta elemen luar bangunan, meliputi sirkulasi area, area terbuka hijau dan tempat parkir

Dari analisis sirkulasi yang telah dilakukan, maka hasil analisis sirkulasi yaitu Sirkulasi utama menuju site dapat diakses melalui jalan veteran. Jalan tersebut menggunakan perkerasan aspal dan memiliki 2 arah kendaraan.

Dari analisis perletakan yang telah dilakukan penulis, maka hasil analisis perletakan adalah Massa bangunan utama diletakkan ditengah site setelah dikurangi oleh garis sepadan bangunan. Pada alternatif 1 lahan yang terdapat dibelakang sepi dan tidak terdapat kegiatan manusia serta lalu lintas kendaraan sehingga area ini dapat menjadi tempat servis seperti untuk bongkar muat, ruang genset dan lain-lain. Sedangkan lahan yang terdapat didepan dan samping bangunan mudah diakses oleh kendaraan sehingga area tersebut cocok untuk digunakan sebagai area publik atau pakiran.

Dari analisis orientasi yang telah dilakukan oleh penulis, didapatkan hasil analisis yaitu muka bangunan kearah jalan utama pada sisi bagian timur, site dibuat memiliki banyak bukaan yang akan digunakan sebagai ruang publik. Sedangkan bagian sisi selatan site dilakukan penambahan vegetasi. Untuk bagian barat daya menjadi akses alternatif atau akses keluar dari bangunan dan dilakukan penambahan vegetasi. Pada bagian sisi barat bangunan diberi tambahan shading atau secondary skin serta vegetasi agar mengurangi panas cahaya matahari yang kurang baik masuk ke dalam bangunan. Sedangkan untuk bagain utara diberikan vegetasi dan bagian barat laut bangunan dibuat solid dan diberikan vegetasi.

Hasil dari analisis zoning adalah publik, semi publik, privat dan servis. Pada bagian publik berada paling depan dekat jalan utama dan menjadi entrance bangunan sehingga memudahkan pengunjung masuk ke dalam site. Pada bagian publik juga berada di sisi kiri di site yang digunakan untuk sirkulasi kendaraan. Arus lalu lintas agar terhindar dari kemacetan. Semi publik pada site digunakan untuk pengunjung maupun pengelola bangunan. Bagian privat terletak agak kebelakang di bangunan supaya mengurangi kebisingan yang masuk dan memiliki akses masuk yang bersifat privasi. Bagian servis terletak paling belakang yang memiliki kebisingan yang cukup tinggi jauh dari gedung utama sehingga tidak mengganggu aktivitas utama yang sedang berlangsung. Hasil analisis yang didapatkan dijadikan Skematik ruang luar yang disajikan pada gambar 2.

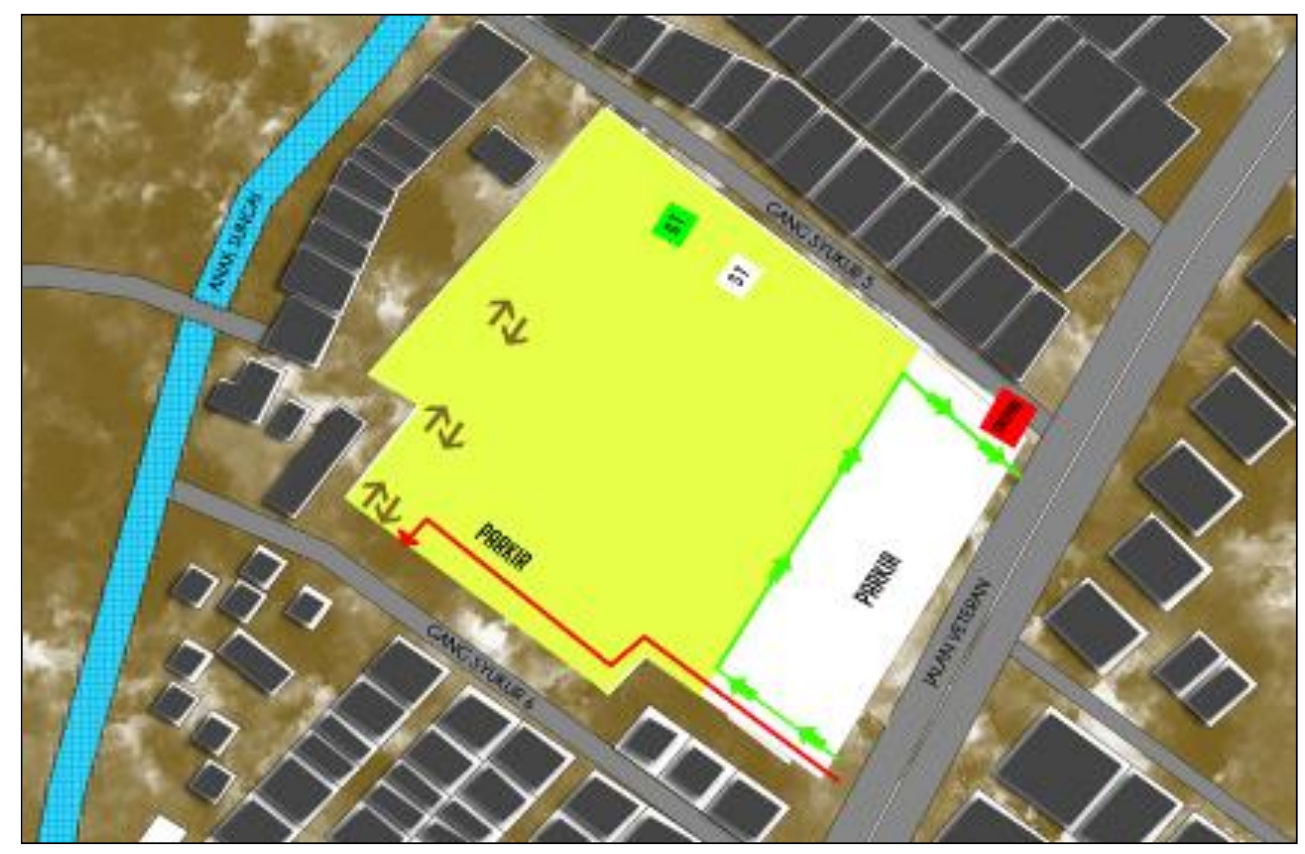

Gambar 2. Skematik Ruang Luar

Sumber: Penulis, 2019 
Transformasi bentuk bersumber dari gagasan dalam fungsi dan konsep filosofis. Ide awal pemilihan bentuk adalah diadaptasi dari tanjak melayu dan kemudian digabungkan dengan hasil analisis internal dan eksternal. Penekanan bentuk digambarkan melalui secondary skin yang dibuat melengkung keatas. Transformasi gubahan bentuk dilihat pada Gambar 3 \& 4.

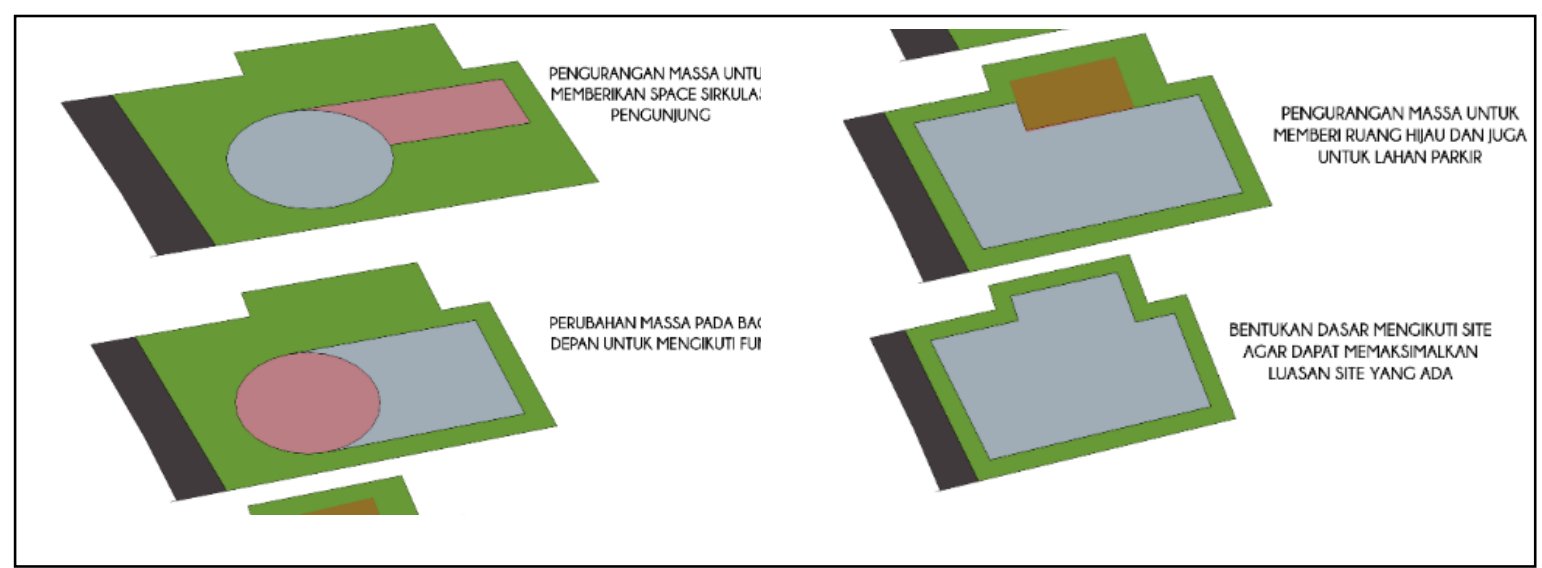

Gambar 3. Transformasi Bentuk

Sumber: Penulis, 2019

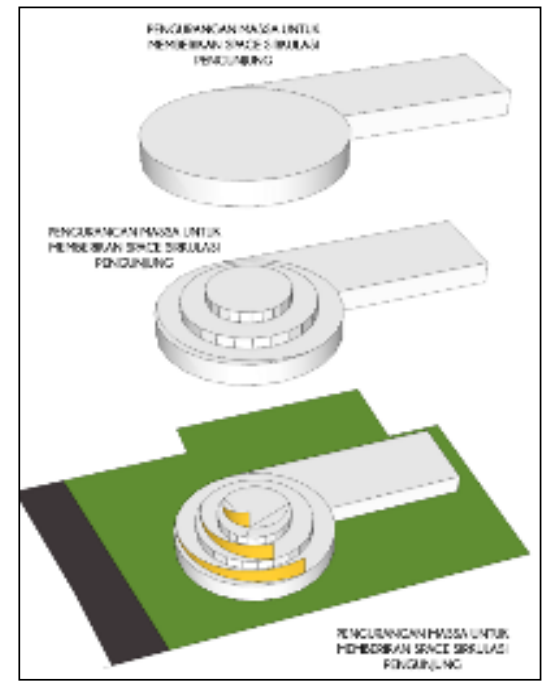

Gambar 4. Transformasi Bentuk Sumber: Penulis, 2019

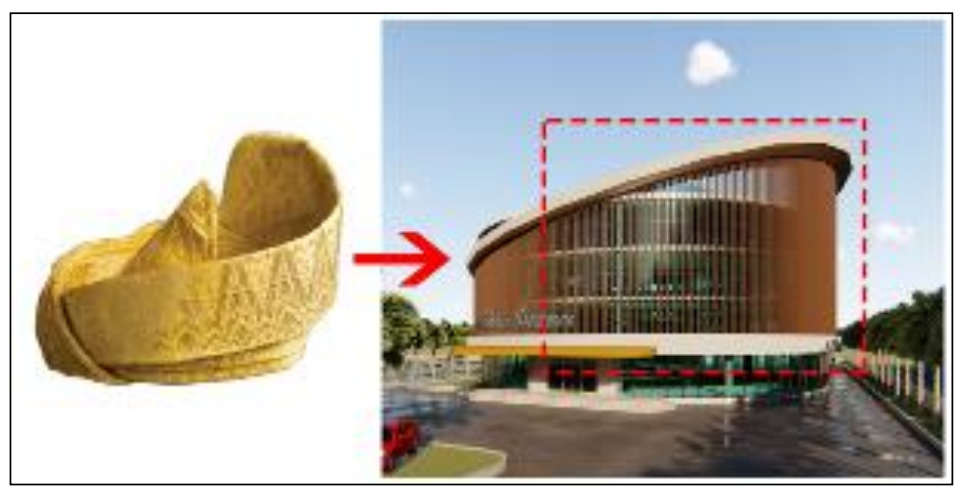

Gambar 5. Gubahan Bentuk

Sumber: Penulis, 2019 
Pada gambar 5 menjelaskan tentang penggunaan bentuk melengkung keatas agar mempertegas bentuk tanjak yang menjulang. Bentuk yang mampu memaksimalkan iklim menjadi perhatian khusus agar bangunan mampu memanfaatkan kondisi yang ada seperti sirkulasi udara sebagai penghawaan alami, dan intensitas cahaya sebagai penerangan alami yang dapat di alirkan ke suluruh bangunan.

Dalam distribusi air bersih menggunakan sistem up feed karena bangunan yang terdiri dari \pm 3 lantai sehingga beban kerja pompa tidak terlalu berat. Perhitungan kapasitas kebutuhan air bersih pada bangunan dilakukan untuk mengetahui penggunaan air besih pada bangunan. Ukuran ground water tank adalah $3 \times 4 \times 3$ meter. Air kotor yang dihasilkan dari toilet dan limbah dapur memerlukan penangan menggunakan tanki septic biotank yang mampu mengelola, mengurai dan menyaring kotoran agar limbah tersebut menjadi limbah cair sehingga layak disalurkan ke riol kota. Pengelolaan air limbah dari wastafel dan limbah dapur akan dikelola menurut sifat air itu sendiri. Hasil dari saniter mengalir ke septictank dengan ukuran $3 \times 3 \times 1,5$ meter. Selain limbah yang berasal dari toilet, limbah dapur yang mengandung lemak dan berminyak dari makanan dapat dialirkan dan dioleh melalui greace trap, kemudian hasilnya diolah kembali di biotank dan dialirkan menuju riol kota.

Bangunan yang dirancang termasuk dalam kategori bangunan yang memiliki kapasitas pelaku dalam jumlah besar sehingga membutuhkan sistem penghawaan yang tepat. Ac $V R V$ merupakan sistem pendingin yang dilengkapi dengan $c p u$, kompresor inverter dan kerja mesin yang terbukti efisien dalam mendinginkan ruangan.

Sumber listrik utama berasal dari PLN yang didukung oleh genset untuk mencegah mati listrik. Kebutuhan listrik harus sesuai dengan standar yang telah ditentukan, kemudian dialirkan melalui gardu induk, lalu dioperasikan oleh panel utama yang terletak di dalam ruangan khusus, sehingga memudahkan pengendalian, pengawasan dan pemeliharaan.

Sistem transportasi pada bangunan menggunakan ramp dan lift. Penggunaan transportasi ramp sebagai transportasi utama dan darurat pada bangunan. Jumlah lantai bangunan tidak lebih dari 4 lantai memungkinkan untuk mneggunakan ramp. Selain ramp transportasi lain yang digunakan yaitu lift. Lift sebagai transportasi pada bangunan dapat memudahkan pengguna bangunan baik untuk orang normal maupun penyandang disabilitas.

Sistem struktur yang digunakan untuk Pusat Fashion Pontianak yakni sistem struktur yang bisa menahan beban bangunan dari gubahan bentuk yang direncanakan tiga lantai. Pondasi sebagai penahan beban yang menopang beban dan menyalurkan tekanan beban ke tanah oleh karena itu pondasi yang digunakan harus memiliki kekuatan dan keawetan serta memenuhi standar. Lokasi perancangan Pusat Fashion Pontianak yang berada di jalan veteran, memiliki jenis tanah gambut yang memiliki karakteristik tanah yang basah, memiliki kadar keasaman yang tinggi, lunak dan memiliki ketebalan tanah gambut mencapai 1-6 meter sehingga pondasi yang cocok untuk digunakan adalah pondasi tiang pancang beton mini pile. Massa bangunan utama terdiri dari 4 lantai yang mana menggunakan bentang lebar sebesar 5 - 8 meter sehingga hal ini dapat mempengaruhi ukuran tiang pancang yang digunakan karena terkait dengan beban yang ditopang. Pendekatan perhitungan kebutuhan dimensi balok dan kolom yang diperlukan berukuran 50x50 cm untuk kolom sedangkan 40x20 cm untuk balok induk. Struktur atas terkait dengan bagian atap bangunan. Atap bangunan terdiri dari rangka atap, bentuk atap dan material penutup atap. Rangka atap menggunakan material yang kuat dan mudah dalam pemasangan. Atap yang digunakan adalah atap dak beton karena merupakan atap yang multifungsi, memiliki daya tahan yang kuat, dapat menghalau panas, tidak mudah terbakar, dan mudah dalam pngerjaannya. Atap dak juga memiliki kemiringan yang berguna untuk mempermudah pengaliran air hujan.

\section{Hasil}

Gambar siteplan dirancang berdasarkan berbagai pertimbangan dalam perancangan, kemudian mengarah pada tata letak bangunan, sirkulasi dan elemen pendukung pada kawasan tersebut. 
Pra rancangan mengarah pada hasil akhir desain yang telah membentuk gambar kerja seperti siteplan, denah, tampak, dan potongan. Pada gambar siteplan dapat dilihat pada gambar $\mathbf{6}$.

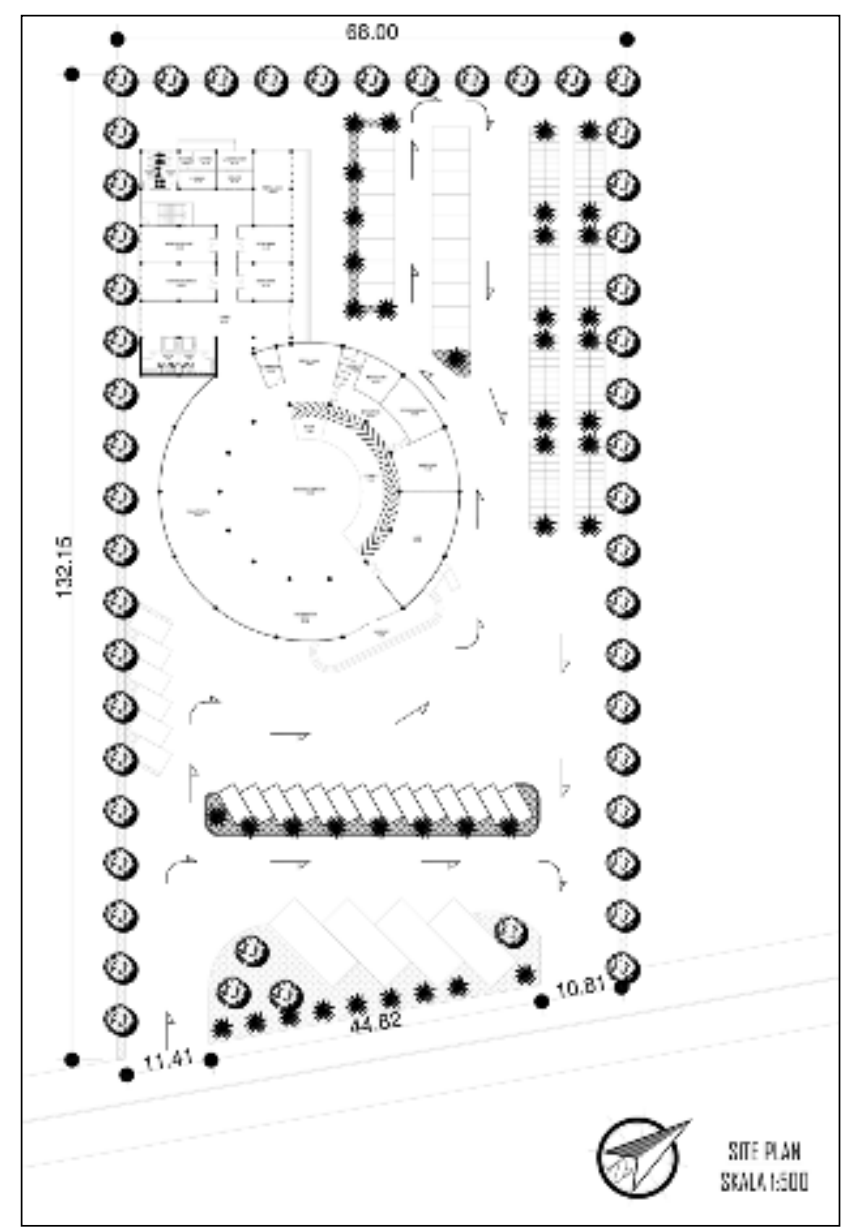

Gambar 6. Siteplan

Sumber: Penulis, 2019

Siteplan Pusat Fashion Pontianak menjelaskan tentang pintu masuk dan pintu keluar site, sirkulasi pelaku eksternal (pengunjung), sirkulasi internal (karyawan/staf), dan sirkulasi servis. Pintu masuk dan pintu keluar site berada di Jalan veteran dan gang syukur 6. Pintu masuk untuk kendaraan roda 4 dan 2 berada di sisi depan kiri site sedangkan pintu keluar mobil berada di sisi kanan site dan area kiri belakang site untuk pintu keluar roda 2. Area parkir kendaraan diletakkan pada depan bangunan utama agar mudah diakses oleh pengunjung. Pengunjung yang menggunakan kendaraan akan masuk ke site kemudian diarahkan untuk drop off pada area depan bangunan utama. Kemudian terdapat akses menuju area parkir yang terletak di depan site. Sedangkan kendaraan yang ingin keluar dapat keluar langsung melalui pintu keluar yang sudah di sediakan. Untuk sirkulasi internal (karyawan/staf) melalui pintu masuk yang berbeda dengan sirkulasi eksternal dan langsung menuju area parkir kendaraan. Pintu keluar sirkulasi internal juga berbeda dengan jalur utama untuk pengunjung. Suasana kawasan Pusat Fashion Pontianak dapat dilihat pada gambar 7. 


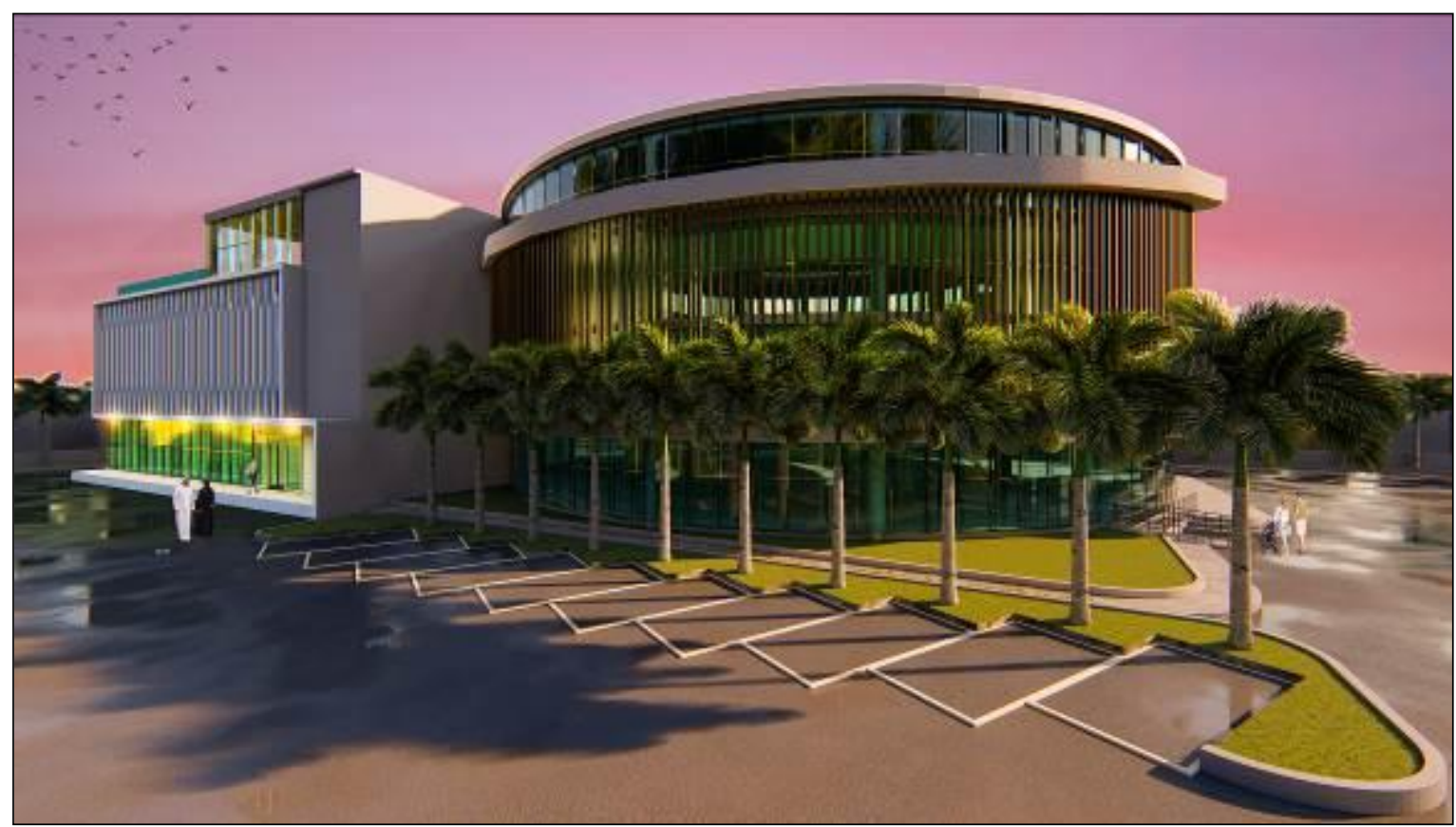

Gambar 7. Suasana Kawasan

Sumber: Penulis, 2019

Gambar denah lantai menunjukkan penataan ruang bangunan dari arah vertikal dan horizontal. Pada gambar denah juga memperlihatkan luasan ruang yang fungsi dan sifatnya telah disesuaikan.

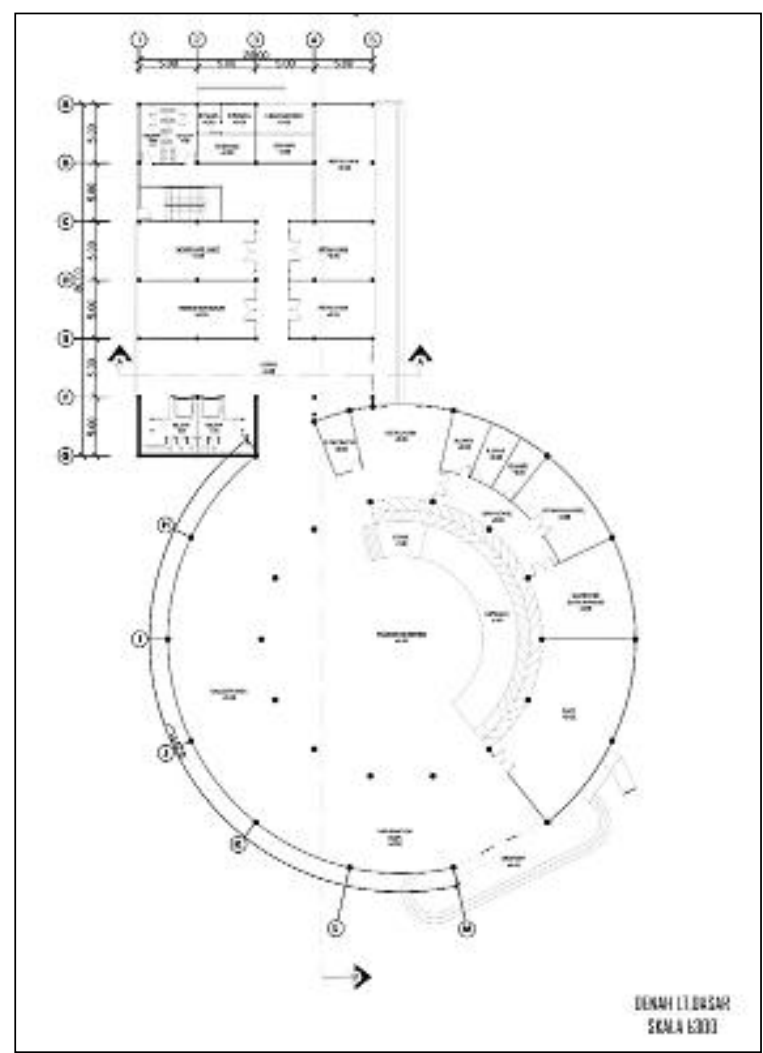

Gambar 8. Denah Lantai dasar

Sumber: Penulis, 2019 
Denah lantai dasar yang berbentuk lingkaran diawali dengan drop off kemudian di dalam bangunan terdapat ruang information desk, cafe, gallery area, fashion exhibition, stage, catwalk, ruang operator, retail kain, ruang backstage, ruang ganti, ruang tunggu model. Lalu pada bangunan yang berbentuk persegi panjang terdapat lobi, toilet, dari sebelah kiri sampai kanan terdapat workshop tenun, workshop jahit, tangga, toilet, ruang teknisi, ruang panel, ruang pompa, gudang, loading dock, dan retail kain.

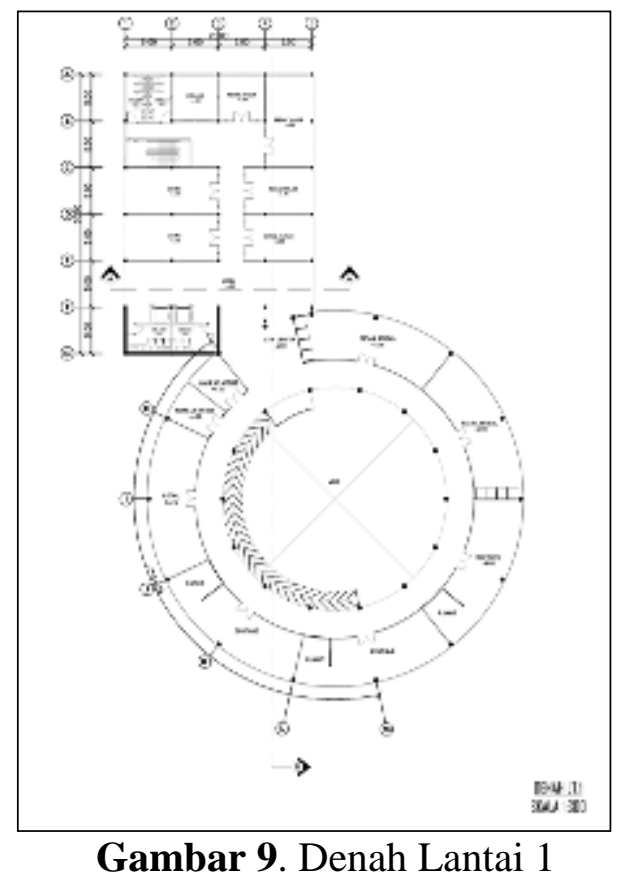

Sumber: Penulis, 2019

Ruangan yang terdapat pada bangunan berbentuk lingkaran di gambar 7 denah lantai 1 antara lain ATM center, retail bridal, boutique, ruang jahit, retail cafe, make up artist, sedangkan yang berbentuk persegi panjang terdapat toilet, lobi, distro, tangga, toilet, gudang, dan retail taylor.

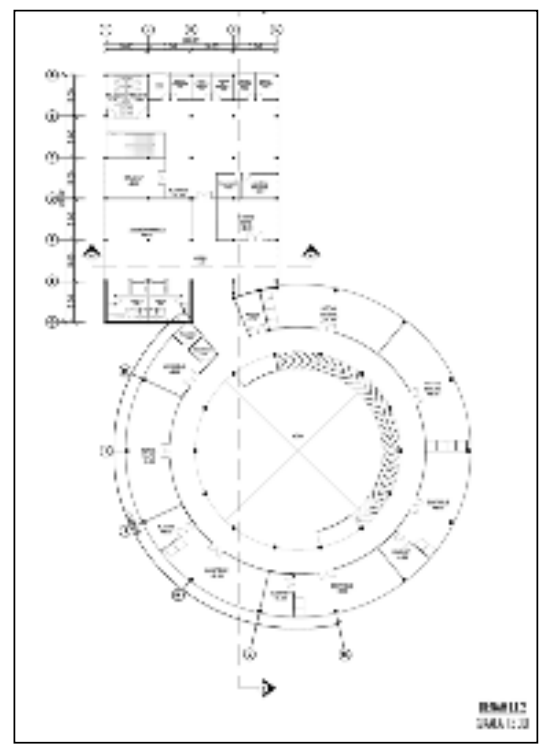

Gambar 10. Denah Lantai 2

Sumber: Penulis, 2019 
Pada gambar 10 denah lantai 2 yang berbentuk lingkarang terdapat ruang make up artist, retail bridal, boutique, ruang jahit, retail cafe, mushola dan ruang wudhu. Sedangkan pada bangunan berbentuk persegi panjang terdapat toilet, lobi, souvenir area, studio foto, ruang absen, ruang rapat, tangga, toilet, pantry, ruang kepala divisi program, ruang kepala administrasi dan marketing, ruang kepala divisi personalia, ruang kepala rumah tangga, ruang divisi humas, ruang manager dan ruang general manager.

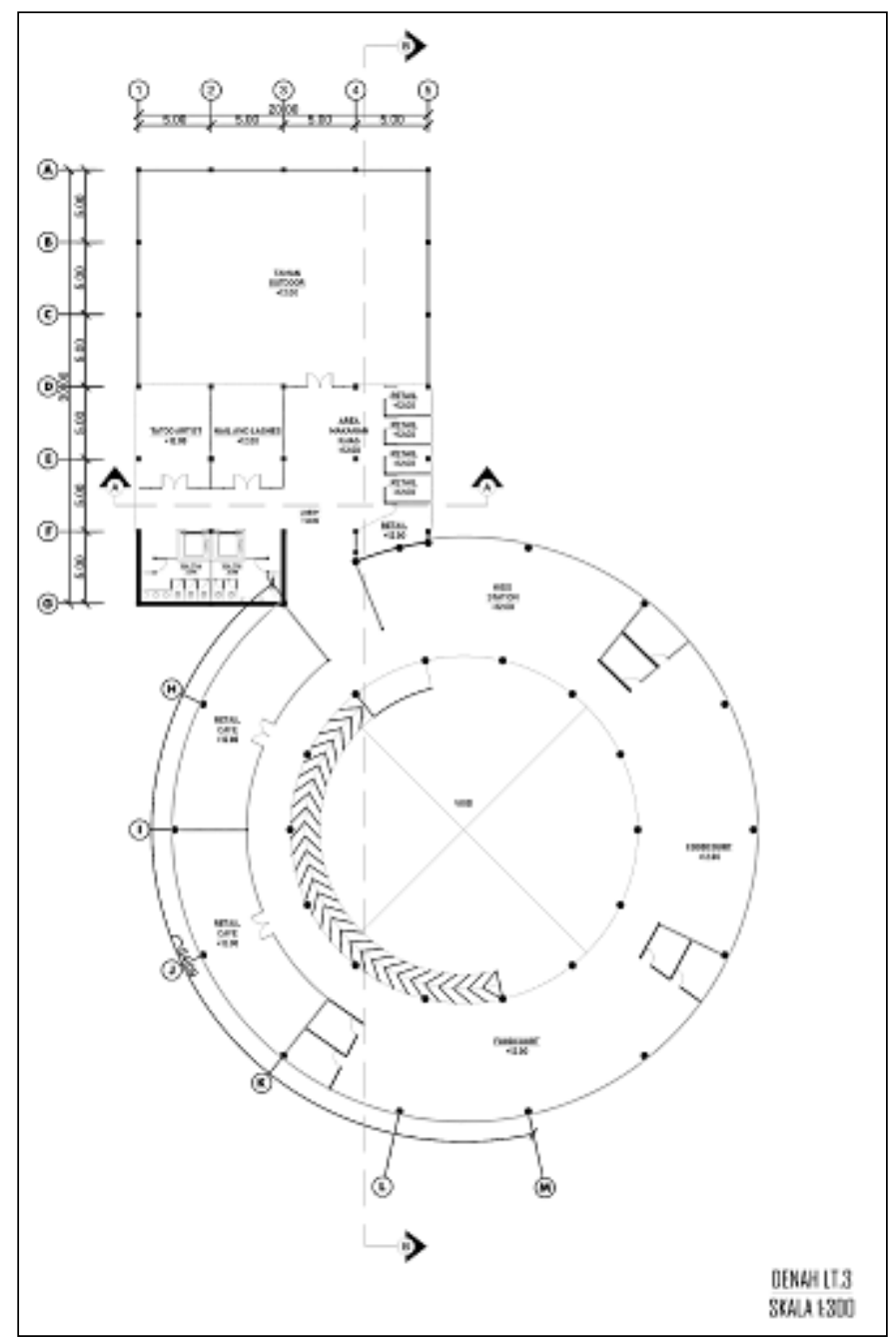

Gambar 11. Denah Lantai 3

Sumber: Penulis, 2019

Gambar 11 denah lantai 3 yang berbentuk lingkaran terdapat ruang kids station, foodcourt, dan retail cafe. Sedangkan yang berbentuk persegi panjang terdapat lobi, toilet, tatoo artist, nail and lashes, area makanan khas, retail, dan taman outdoor.

Gambar tampak akan memperlihatkan eksterior dan visual bentuk bangunan paralel. Pada gambar tampak akan memperlihatkan bentuk bangunan dari empat sudut: depan, belakang, kanan dan kiri. Tampak dari gedung Pusat Fashion Pontianak Memiliki kesan visual arsitektur yang megah, mewah, modern dan futuristik dengan mengadaptasi bentuk dari tanjak melayu pada bagian secondary skinnya. Berikut tampak Pusat Fashion Pontianak 


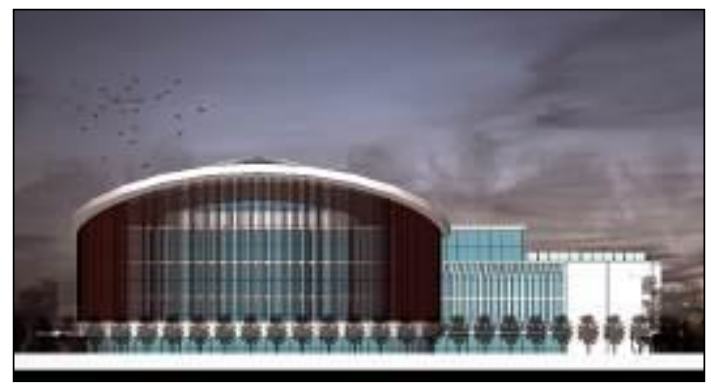

Gambar 12. Tampak Kiri

Sumber: Penulis, 2019

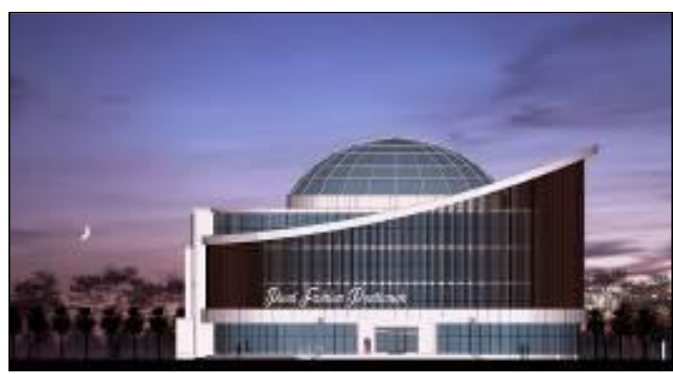

Gambar 13. Tampak Depan

Sumber: Penulis, 2019

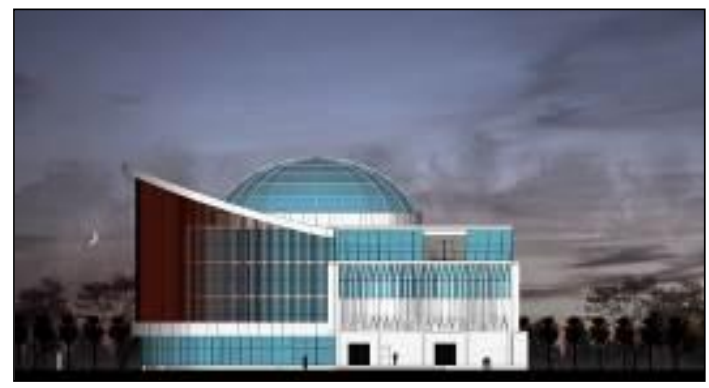

Gambar 14. Tampak Belakang

Sumber: Penulis, 2019

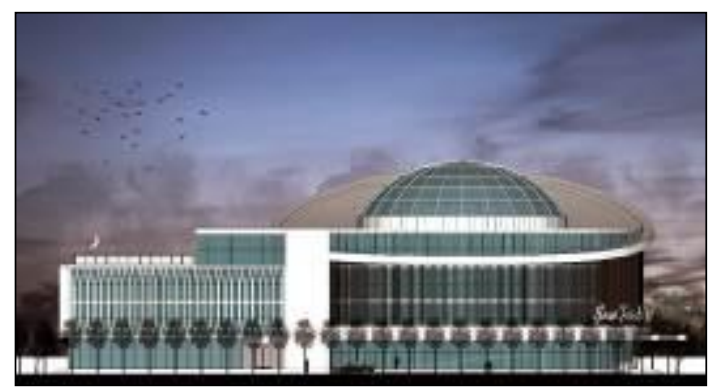

Gambar 15. Tampak Kanan

Sumber: Penulis, 2019

Gambar potongan adalah gambar yang menunjukkan sebuah gambar yang terpotong secara vertical. Biasanya gambar potongan akan mengacu pada ukuran ketebalan dan spesifikasi teknis bangunan tersebut. Setelah gambar dipotong, semuanya terlihat seperti dari ketinggian tembok hingga pondasi, ketebalan sloff atau ring balok, dan masih banyak gambar lainnya yang bisa dilihat dari gambar potongan tersebut. Pada gambar potongan juga memperlihatkan suasana dalam ruangan secara paralel sebagaimana yang terlihat pada gambar 16 dan gambar 17. 


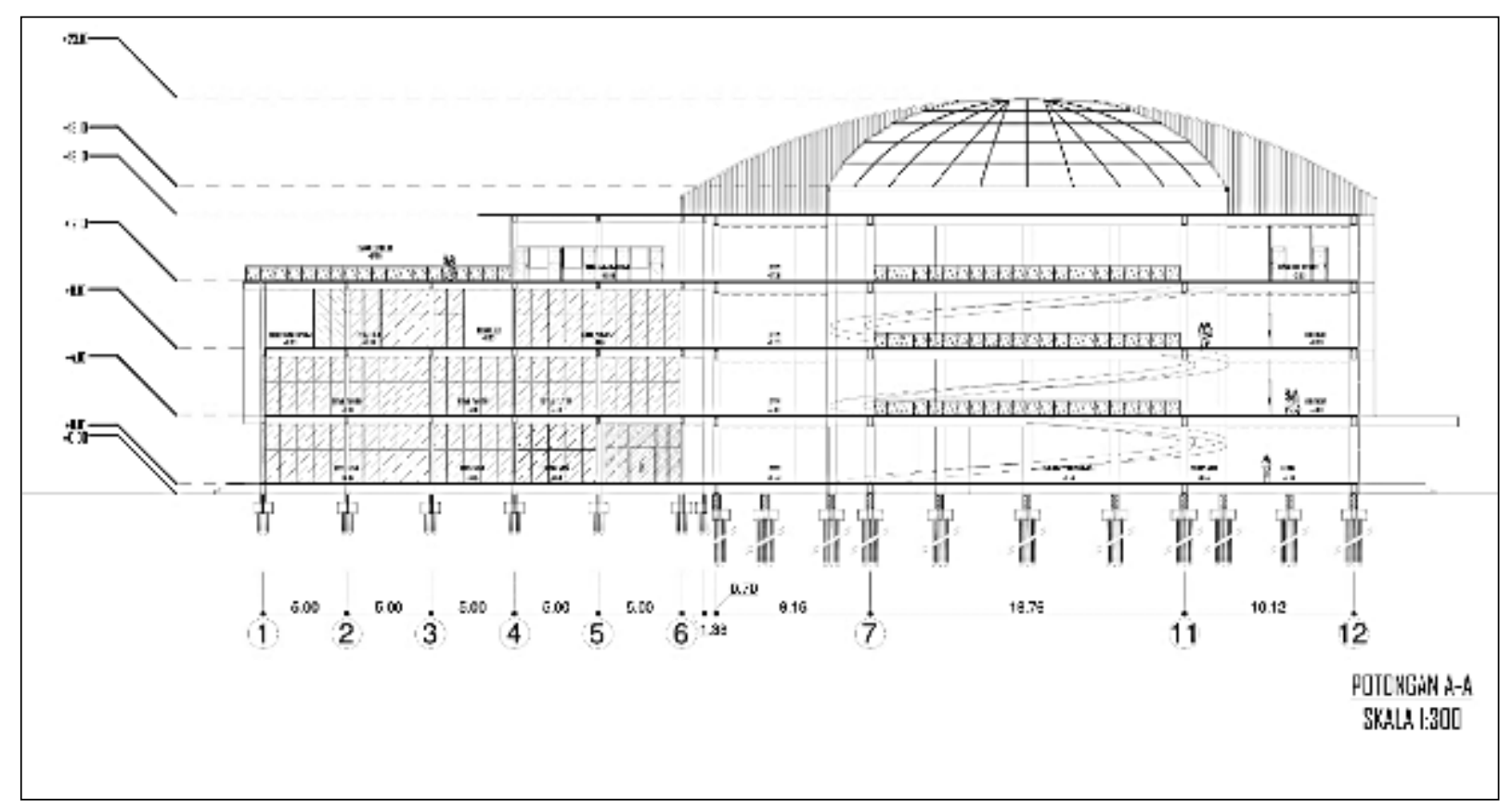

Gambar 16. Potongan A-A

Sumber: Penulis, 2019

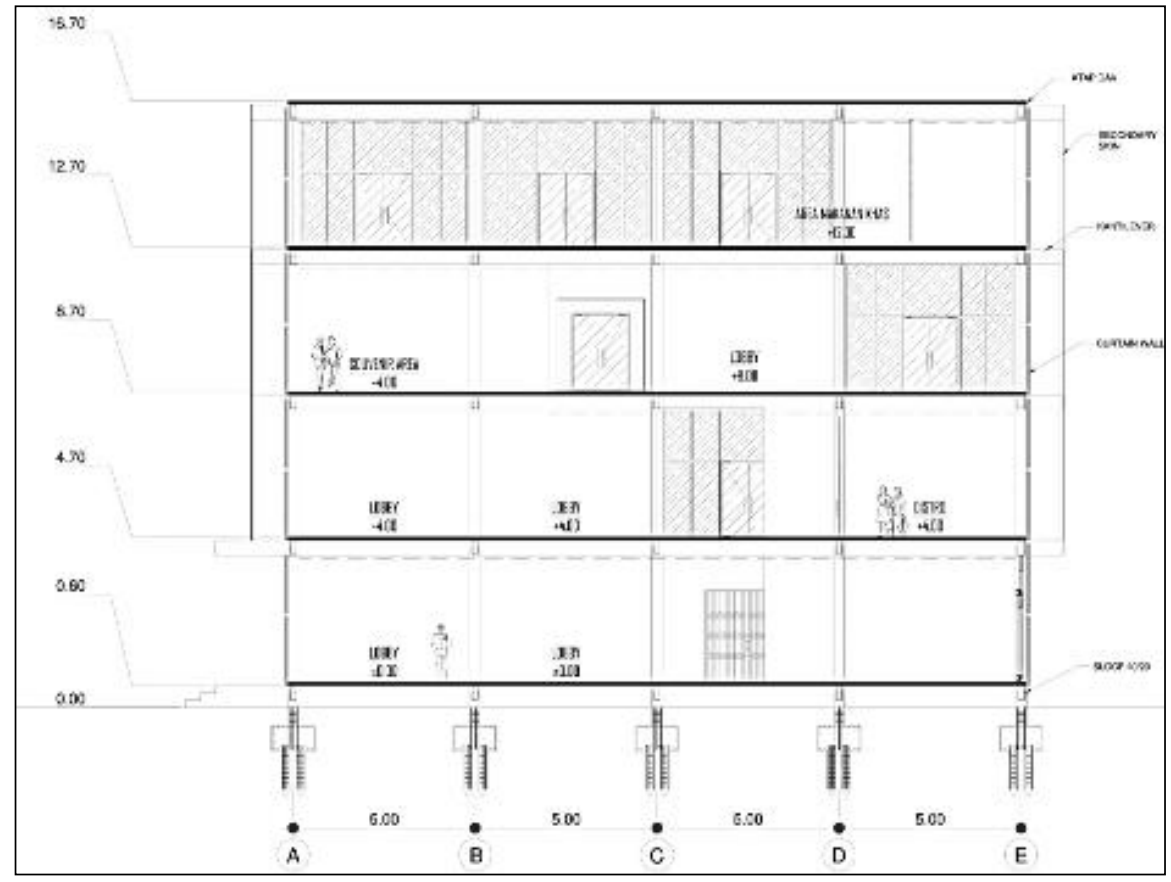

Gambar 17. Potongan B-B

Sumber: Penulis, 2019

Desain akhir dari gedung Pusat Fashion Pontianak akan diperlihatkan pada gambar ilustrasi tiga dimensi. Citra tiga dimensi tersebut menunjukkan suasana di luar gedung yang dapat dilihat dari sudut pandang perspektif, dan memiliki ciri-ciri yang saling berkaitan.

Fasad bangunan menggunakan material beton, kayu, kaca, dan alumunium composite panel. Penggunaan kaca agar mendapatkan kesan modern, dan bagian depan yang berbentuk lingkaran mengikuti fungsi. Bagian kaca melingkar akan dilapisi dengan secondary skin yang menggunakan 
kayu kamper. Untuk meningkatkan efisiensi bangunan, penggunaan bentuk yang dinamis, pemilihan material yang tepat serta pemilihan alat dan komponen pada bangunan juga menjadi pertimbangan.

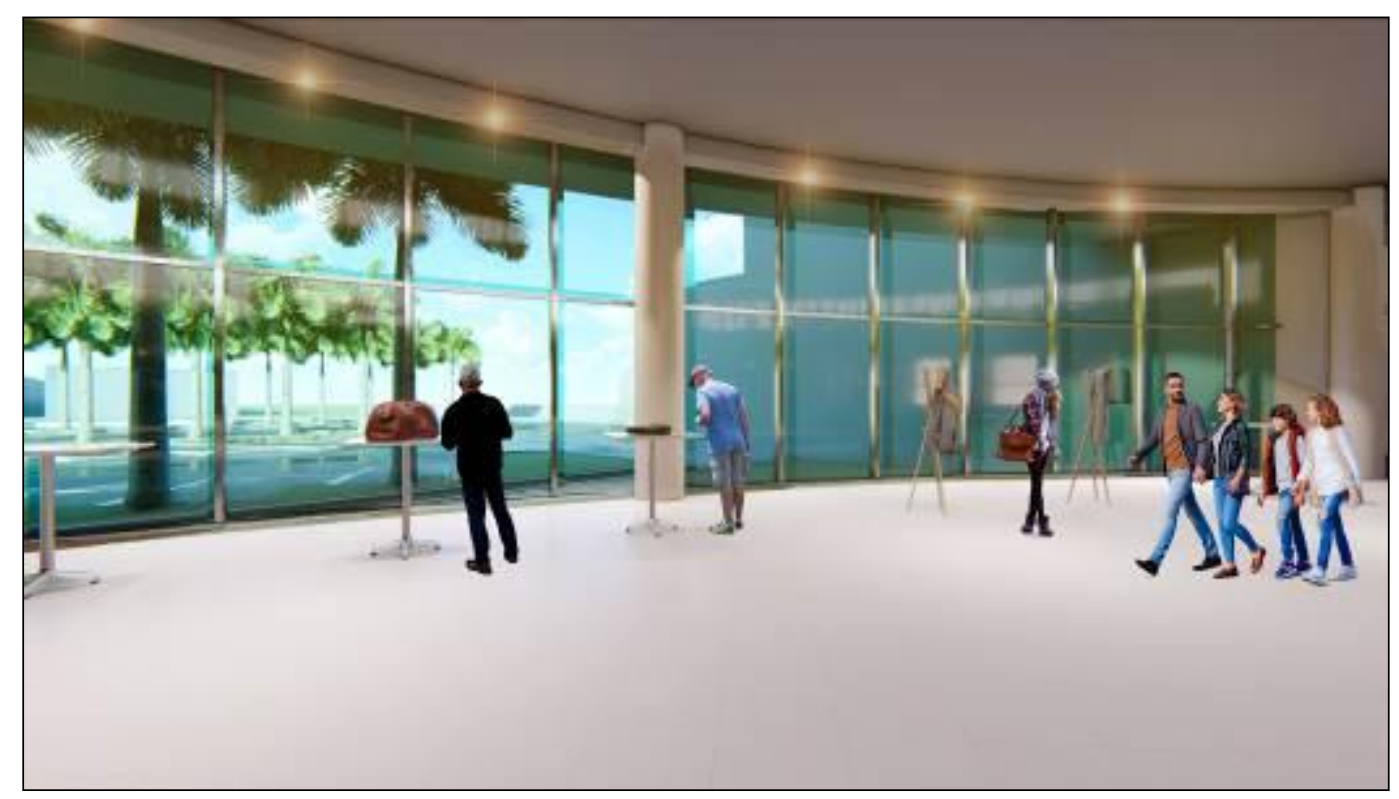

Gambar 18. Suasana Interior

Sumber: Penulis, 2019

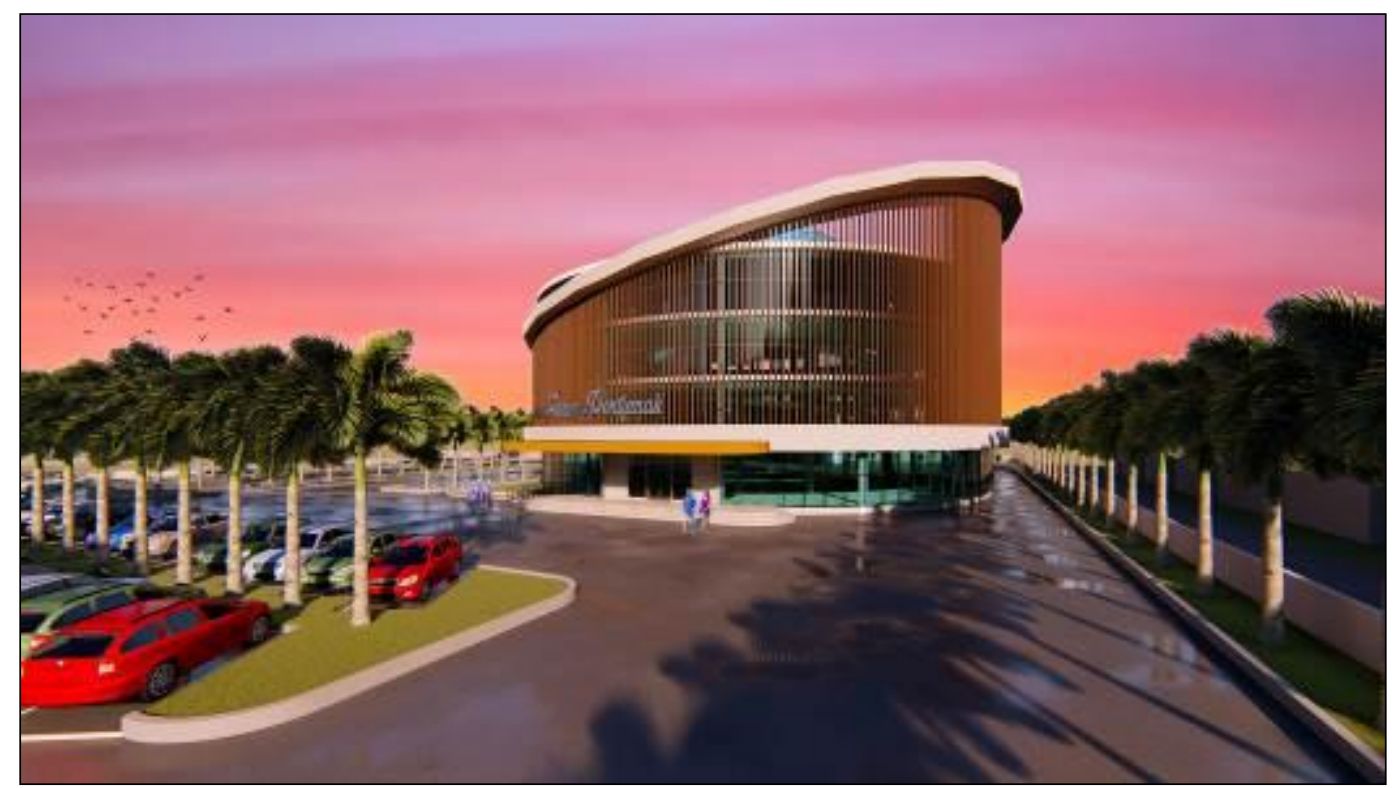

Gambar 19. Suasana Eksterior

Sumber: Penulis, 2019

\section{Kesimpulan}

Pusat Fashion Pontianak merupakan tempat untuk mewadahi segala yang berhubungan dengan fashion dan juga sebagai galeri untuk memamerkan karya seni dibidang fashion daerah Kalimantan Barat serta menjadikan bangunan ini sebagai landmark bagi kalangan pecinta fashion. Konsep Perancangan Pusat Fashion Pontianak sendiri adalah bangunan yang mengadopsi bentuk dari tanjak melayu sebagai bentuk utama. Saran penulis untuk perancangan Pusat Fashion Pontianak adalah dengan adanya gedung yang akan memfasilitasi hal yang berkaitan dengan fashion diharapkan mampu meningkatankan promosi produk-produk lokal yang ada di Provinsi Kalimantan Barat ini. 


\section{Ucapan Terima Kasih}

Ucapan syukur kepada Tuhan Yang Maha Esa, kepada orang tua penulis, kepada para dosen pembimbing Proyek Tugas Akhir yaitu bapak Hamdil Khaliesh, S.T., M.T. selaku pembimbing utama dan bapak Irwin, S.T., M.T. selaku pembimbing pendamping yang rela meluangkan waktu disela sela kesibukannya untuk membimbing memberikan kritik dan saran untuk penulis. Kepada seluruh dosen dan staf prodi arsitektur lalu teman-teman, kedua orang tua dan semua pihak yang telah banyak memberikan doa dan dukungannya pada proyek tugas akhir ini, penulis mengucapkan terima kasih.

\section{Daftar Acuan}

Kamus Besar Bahasa Indonesia. (2019, December 18). Pengertian Fashion. Retrieved from https://kbbi.web.id/fashion Kamus Besar Bahasa Indonesia. (2019, December 18). Pengertian Pusat. Retrieved from https://kbbi.web.id/pusat Poerwadarminta, W.J.S. (2003). Kamus Umum Bahasa Indonesia. Jakarta: Balai Pustaka

Strathern, A., Polhemus, T., \& Procter, L. (1979). Fashion and Anti-Fashion. An Anthropology of Clothing and Adornment. London: Thames \& Hudson

Yunita, C. (2019, December 18). Jogja Fashion Center Di Yogyakarta. Retrieved from http://e-journal.uajy.ac.id/ 